\title{
The timing of prednisolone dosage and its effect on morning stiffness in rheumatoid arthritis
}

\author{
M. DE SILVA, A. BINDER, AND B. L. HAZLEMAN \\ From the Department of Rheumatology Research, Addenbrooke's Hospital, Hills Road, Cambridge
}

SUMMARY Forty-one patients with rheumatoid arthritis (RA) maintained on low dose prednisolone (mean $5.8 \mathrm{mg}$ ) participated in a double-blind cross-over study to determine the effect of timing (morning or night) of prednisolone dosage on morning stiffness. Prednisolone given at night resulted in a significantly shorter duration of morning stiffness $(p=0.0001)$ than did an equivalent dose given in the morning.

Key words: arthritis, rheumatoid, steroids, administration, timing and clinical effect.

In the treatment of RA the amelioration of unacceptable morning stiffness unresponsive to standard clinical measures is an indication for the use of low-dose steroids. ${ }^{1}$ Whether the time at which steroids are taken affects their efficacy or safety is uncertain. In $1958 \mathrm{Di}$ Raimondo and Forsham ${ }^{2}$ recommended a single morning dose as being safe and effective. Myles and Daly ${ }^{3}$ and Klinefelter et $_{\text {al. }}{ }^{4}$ endorsed this view but noted that some RA patients needed a nocturnal dose to control morning stiffness. Kowanko et al. ${ }^{5}$ found no difference in pain relief and morning stiffness nor any evidence of hypothalamic-pituitary-adrenal (HPA) axis suppression whatever time of the day low-dose steroids were used; nevertheless they also recommended a single morning dose. On the other hand Nugent $e t$ $a l .{ }^{6}$ and de Andrade et al. ${ }^{7}$ who looked specifically for the effect on morning stiffness, found a nightly dose more effective than an equivalent morning dose. We therefore decided to clarify this important practical aspect by conducting a double-blind crossover study on the effect of timing (morning or night) of steroid dose on morning stiffness.

\section{Patients and methods}

Forty-one patients with classical or definite RA (ARA criteria ${ }^{8}$ ) were included in the study. Details of the patients (Table 1) and of steroid therapy data (Table 2) are shown. Particular care was taken to ensure that the antirheumatic medication, including

Accepted for publication 12 June 1984.

Correspondence to Dr M. De Silva. Prince Charles Hospital, Merthyr Tydfil, Glamorgan.
Table 1 Patient details $(n=4 I)$

\begin{tabular}{ll}
\hline Male:female & $10: 31$ \\
Age & Mean $63 \cdot 6$ years (27-81) \\
Disease duration & Mean $11 \cdot 1$ ycars $(1-30)$ \\
Functional class (Stcinbrocker) & Class I =2 \\
& Class II $=18$ \\
& Class III $=21$
\end{tabular}

Table 2 Details of steroid therapy

\begin{tabular}{ll}
\hline $\begin{array}{l}\text { Duration of therapy } \\
\text { Daily steroid dosage }\end{array}$ & Mean $4 \cdot 4$ years $(3$ months-20 years $)$ \\
Timing prior to study: & \\
Morning only & 18 patients \\
Divided dosage & 18 patients \\
Evening-only & 3 patients \\
Mid-day-only & 2 patients \\
\hline
\end{tabular}

steroid dosage, had been maintained at a stable level for at least three months prior to the study. Thirteen patients were receiving concurrent penicillamine or sodium aurothiomalate therapy, four azathioprine, and 38 a variety of non-steroidal anti-inflammatory agents. No change in the drug therapy was permitted during the study except for paracetamol, which was used as a rescue analgesic.

The patients were asked to take their study tablets on retiring (10 pm-11 pm) and on rising (6 am-7 am) with milk but not a major meal. The total daily maintenance dose of prednisolone (to the nearest 1 $\mathrm{mg}$ ) was given as uncoated $1 \mathrm{mg}$ tablets with a similar number of identical placebo tablets. For each patient the study was divided into two one-monthlong phases. In each phase the night dose contained 
prednisolone during one month and the morning dose during the other month. The sequence of night and morning prednisolone was prearranged according to a randomised schedule and was not revealed to the patient or the observer until the whole study was completed.

The patients were given diaries to make a daily record of: $(a)$ The duration of morning stiffness (MS on a 7 -point scale $(1=0-15$ minutes, $2=15-30$ minutes, $3=30-45$ minutes, $4=45-60$ minutes, $5=60-120$ minutes, $6=120-180$ minutes and $7=$ more than 180 minutes). (b) A daily comment of well-being, side-effects, and any change in their joint symptoms.

At the end of the study the patients were also asked to state their preference for the first or second phase of therapy without knowing the sequence of therapy.

\section{Results}

Morning stiffness (MS). A mean score was calculated by means of the seven-point scale for each patient for each week of therapy. From these results a mean weekly score for MS was obtained for all the patients on morning and night therapy (Fig. 1) during each phase of the study. Two-way analysis of variance on the four mean weekly scores for MS while on morning and night therapy (Table 3) showed that neither the order of therapy nor within-week therapy gave any significant variation. Because of this homogeneity, a mean score for MS was calculated over each of the four-week therapy
Table 3 Mean weekly scores of morning stiffness in all the 41 patients while on morning and night prednisolone

\begin{tabular}{lllll}
\hline \multicolumn{5}{l}{ Week of therapy } \\
\cline { 2 - 5 } & 1 & 2 & 3 & 4 \\
\hline Morning prednisolone & $4 \cdot 11$ & $4 \cdot 10$ & $4 \cdot 04$ & $4 \cdot 03$ \\
Night prednisolone & $3 \cdot 28$ & 3.26 & $3 \cdot 26$ & $3 \cdot 11$ \\
\hline
\end{tabular}

Table 4 Comparison of mean scores for morning stiffness while on morning (am) and night $(\mathrm{pm})$ prednisolone

\begin{tabular}{lllllll}
\hline & $\begin{array}{l}\text { Mean score } \\
\text { am } \\
\text { prednisolone }\end{array}$ & $\begin{array}{l}\text { Mean score } \\
\text { pm } \\
\text { prednisolone }\end{array}$ & $\begin{array}{l}\text { Mean } \\
\text { difference }\end{array}$ & $p$ \\
\hline $\begin{array}{l}\text { Morning } \\
\text { stiffness }\end{array}$ & 41 & 4.08 & 3.23 & 0.8549 & 4.48 & 0.0001 \\
\hline
\end{tabular}

periods. Comparison of these means (Table 4) showed significantly less morning stiffness $(p=0.0001)$ with night administration. MS scores in the individual patients (Fig. 2) irrespective of the order of administration were shorter in 30 patients (markedly so in 16) on night therapy and seven patients (markedly in two) on morning therapy. Four patients showed no difference in MS between the two phases of the study. The extent of change in MS did not appear to be related (Fig. 3) either to the dose or duration of steroid therapy prior to the study.

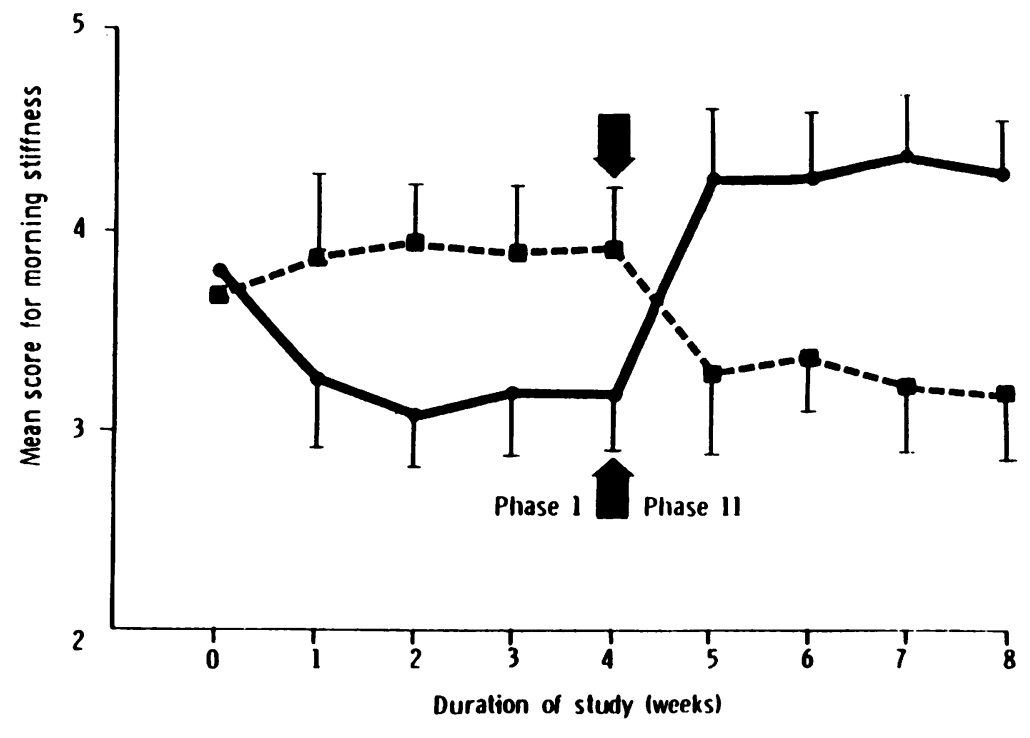

Fig. 1 The mean weekly score for morning stiffness in both phases of the study. 


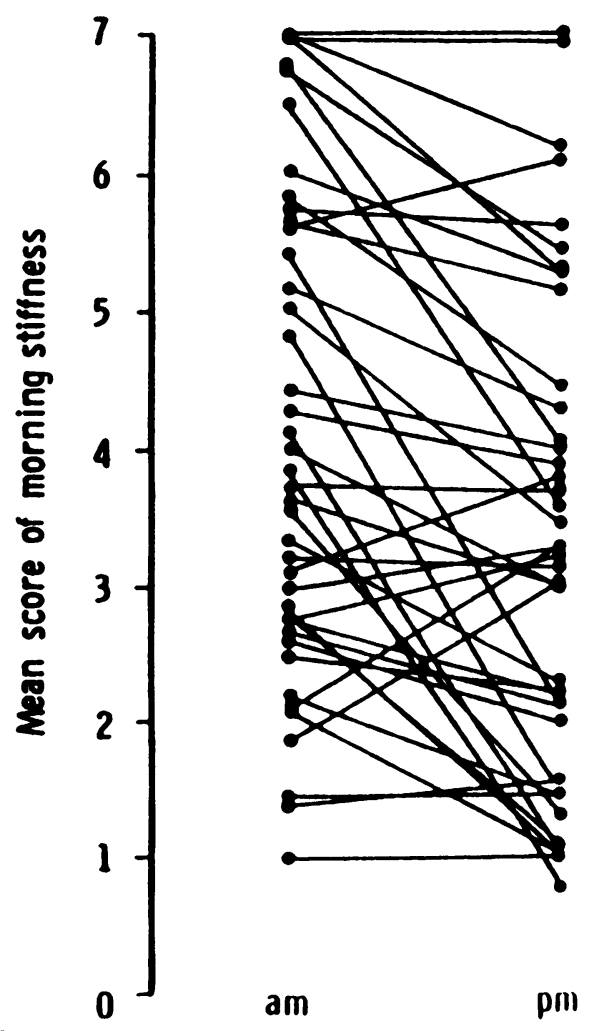

Fig. 2 The severity of morning stiffness in each of $4 I$ patients given their maintenance prednisolone in the morning (am) and evening ( $\mathrm{pm}$ ) irrespective of order of administration.

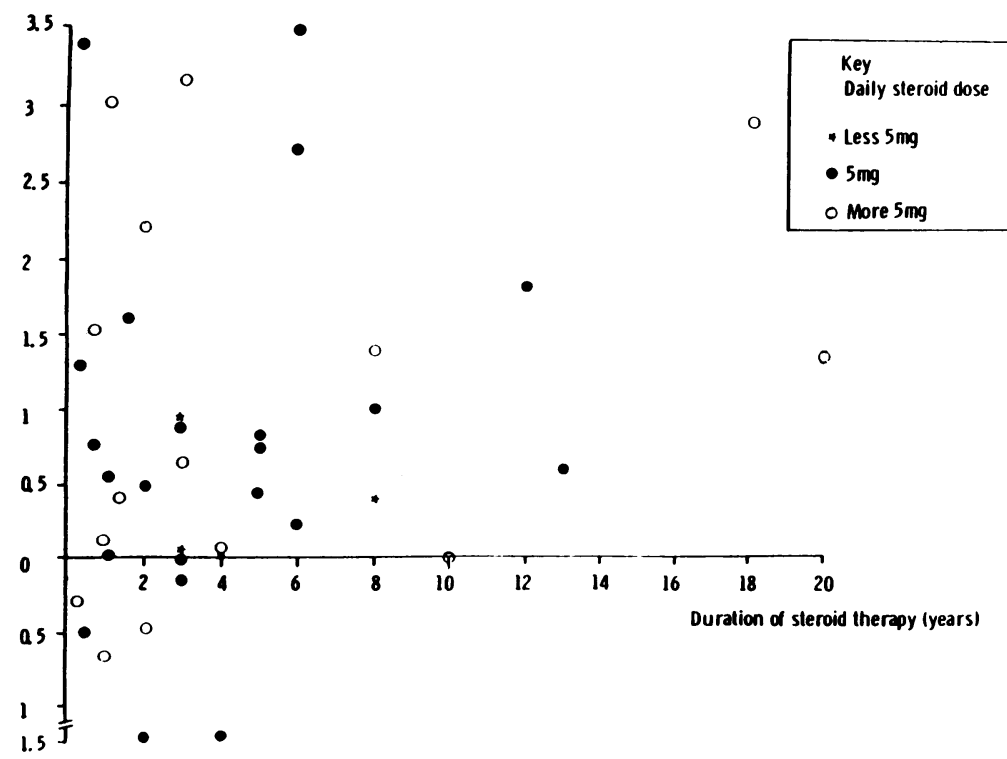

Table 5 Patient preference

\begin{tabular}{lrc}
\hline & $n$ & $\%$ of total \\
\hline Morning prednisolone & 5 & $12 \%$ \\
Night prednisolone & 16 & $39 \%$ \\
No preference & 20 & $49 \%$ \\
\hline
\end{tabular}

Patient preference. Sixteen patients (Table 5) expressed a preference for night and five for morning therapy. Twenty patients had no strong preference. Non-parametic statistical analysis (sign test) showed a significant preference $(p<0.05)$ for the night therapy.

Withdrawals. These comprised two out of 41 . One in the first week of the study was a patient who required surgery for a gastrointestinal haemorrhage, and one withdrew in the last week (morning dose) because of unacceptable morning stiffness.

\section{Discussion}

At present persistent morning stiffness remains one of the few indications for the use of low-dose steroids in the treatment of RA. Conflicting suggestions have been made as to the best time at which they should be given. The case for giving steroids in the morning has been based more on safety than on efficacy. ${ }^{9}$ There is little evidence that, when small doses of steroids are used, the time at which they are

Fig. 3 The effect of dosage and duration of steroid therapy prior to the study on the extent of change in morning stiffness from morning (am) to night (pm) administration. 
given has a significant effect on HPA axis suppression. However, there is sufficient evidence that HPA axis suppression is dependent on the type, dose, and duration of steroid therapy. Therefore if efficacy in terms of the relief of morning stiffness is affected by the time at which steroids are given, the use of the drug at the optimal time may permit the smallest possible dose to be used.

In a controlled double-blind trial the results of which were analysed carefully by appropriate statistical methods we, like de Andrade et al., ${ }^{7}$ have found that, when low-dose prednisolone is used for the relief of morning stiffness in RA, night time administration is more effective than an equivalent dose given in the morning. Although a majority of our patients were taking prednisolone in the morning prior to the study, there was a significant preference $(p<0.05)$ for a night dose at the end of the study, suggesting that general wellbeing too may be favourably affected by an evening dose.

We thank Roussel Laboratories for supplying the prednisolone and placebo tablets and Miss S. Roberts, Department of Community Medicine. University of Cambridge, for the statistical analysis.

\section{References}

1 Barnes C G. Rheumatoid arthritis. In: Currey H L F, ed. Mason and Currey's Clinical Rheumatology. London: Pitman Medical. 1980.

2 Di Raimondo V C. Forsham P H. Some clinical implications of spontancous diurnal variation in adrenal cortical secretory activity. Am J Med 1956; 21: 321-3.

3 Myles A B. Daly J R. Corticosteroid and ACTH treatment: principles and problems. London: Arnold. 1974: 66-81.

4 Klinefelter H F. Winkenwerder W L. Bledsoe T. Single daily dose prednisone therapy. JAMA 1979; 241: 2721-3.

5 Kowanko I C. Pownall R. Knapp M S. Swannell A J S. Mahoney P G C. Time of day of prednisolone administration in rheumatoid arthritis. Ann Rheum Dis 1982; 41: 447-52.

6 Nugent C A. Ward J, MacDiarmid W D. McCall J C. Baukol J. Tyler F H. Glucocorticoid toxicity: single contrasted with divided daily doses of prednisolone. J Chron Dis 1965; 18: 323-32.

7 Andrade J R de. McCormick J N. Hill A G S. Small doses of prednisolone in the management of rheumatoid arthritis. Ann Rheum Dis 1964: 23: 158-62.

8 Ropes M W. Bennett G A. Cobb S. Jacox R. Jessar R A. 1958 revision of diagnostic criteria of rheumatoid arthritis. Ann Rheum Dis 1959: 18: 49-51.

9 Jasani M K, Diver M J, Bell A M, Dalakos T G, Buchanan W W. Some clinical observations on the diurnal rhythm of plasma cortisol (11-OHCS) in patients with rheumatoid arthritis treated with oral corticosteroid drugs. Curr Med Res Opin 1974; 2: 373-86.

\section{Book review}

Clinics in Rheumatic Diseases: Inflammatory Disorders of Muscle. Edited by B. M. Ansell. Pp. 216. $£ 12 \cdot 50$. Saunders: London. 1984.

Like most Clinics this multiauthor book reflects a diversity of opinions. In this case, within the narrow field dealt with by the book, there is considerable overlap in the material dealt with in the various chapters. The apparent repetition, for instance the aetiology, pathology, and treatment turning up almost everywhere - despite each having chapters of their own - is off-putting at first sight. Yet, in fact, the information within these contributions is different, rarely repetitive, and simply reflects the lack of decisive, consensus views in this field at present. I liked the suggestion that the criteria for classifying cases for prospective studies are different from those needed for immediate clinical management in our current state of ignorance. Nevertheless it is off-putting to find two different overlapping classifications presented in one chapter (and then to find that neither is used in a later chapter on pathology).

There are some oddities and omissions - for instance I would have liked to have seen an in-depth discussion of associated pulmonary disease in polymyositis, which is perhaps a more common clinical problem than cardiac involvement which does merit a separate section. Also odd contributions - such as those on malignancy or on histology - seem tired rewrites, suggesting that a new immunopathological approach might be valuable, as in renal disease. Nevertheless, there is a valuable round up of recent material in most of the reviews. This includes a timely reminder of both old and new aspects of infective myositis together with a very good chapter on its occurrence in immunodeficiency.

I would certainly commend the book to all physicians interested in connective tissue diseases. The interested reader who peruses it from cover to cover will find a good deal of useful information and discover those areas of disagreement which clearly require further study. The quick browser hoping for a dogmatic authoritative statement may be disappointed. This is perhaps a fair comment on the current state of the art in understanding these uncommon but important disorders. 